\title{
Design and Application of Multi-screen VR Technology in the Course of Art Painting
}

\author{
http://dx.doi.org/10.3991/ijet.v11i09.6126 \\ Chang Pan \\ University of Science and Technology Liaoning, Anshan, China
}

\begin{abstract}
Through introducing VR technology, multiscreen display technology and the necessity of application of VR technology in teaching and combining the course example of Art Painting, this paper expounded the basic method and realization approach of VR technology application in network teaching. First of all, virtual teaching and virtual experiment were achieved, and then online storage and sharing of Art Painting teaching content were achieved to reach the purpose of well mastering painting skills, theory and course features under network teaching environment.
\end{abstract}

Index Terms-VR technology, Art Painting course, teaching application

\section{INTRODUCTION}

VR technology, i.e. virtual reality technology, is an interactive 3D dynamic landscape presentation technology which utilizes computer simulation principle to create and experience virtual world. Meanwhile, it is an important development branch of computer simulation technology [1].

Since VR technology has such advantages as superstrong experience and virtual dynamic property, many experts and scholars in domestic and oversea education field have started to try to study the introduction of VR technology in modern education and teaching in recent years [2]. Relevant research achievements also spring up continuously. For example, Erlandson et al. [3] studied a cooperative, cognitive and inquiry-based learning mode under VR environment, applied this mode in teaching practice of college science courses and gained great effects. Yuan [4] explored the application strategy of VR technology in college Acupuncture and Moxibustion Therapy course. The practice proves that the introduction of VR technology can improve acupuncture and moxibustion teaching level because of its simulation and interaction features. Liu [5] designed a VR learning and teaching system and applied this system in Art Painting course teaching. This system has excellent interactivity and dynamic property. Tian [6] studied the application of "Motion Capture Technology" in VR technology in art painting teaching. Tian [7] deeply explored theoretical feasibility of integration of art painting and VR technology in teaching.

The researches of the above scholars are strongly advanced. They not just study VR technology from technological perspective, but also deeply analyze the feasibility of integration of VR technology and modern education to create a new reaching form. Thus, their researches can offer certain reference for this paper. However, few researches involve teaching practice pattern of VR technol- ogy and art painting production, platform development and technical maintenance. Meanwhile, when users use the display effect of VR technology, their experience and requirements for multi-screen display control become more and more diversified. For example, different elements can be displayed as required, including picture, PPT, video animation and application program window etc. The display can be operated and controlled conveniently and fast. The number of screens can be allocated at random. However, current multi-screen technology operation is not flexible enough. Screen display content allocation cannot achieve diversified and differential display. In addition, the number of controllable display screens is limited and operation control is complex. These problems restrict the application of VR technology in multi-screen display.

This study is just based on the above background. Firstly, VRML modeling and VRML-JAVA [8] synchronous coordination were combined with SQL Server database technology to construct a teaching platform. This platform has such functions as virtual management, cooperative learning, intelligent evaluation and teaching resource storage. Secondly, a multi-screen display control method used for demonstration system could be provided to solve the problems of complex multi-screen display customization, non-flexible display allocation, single display element, complicated operation control and limited number of screens.

\section{Design OVERVIEW OF TEACHING PLATFORM BASED ON VR TECHNOLOGY}

\section{A. Analysis of design demand}

Teaching platform development based on VR technology is an urgent demand for teaching reform of college Art Painting course. In traditional mode, Art Painting teaching is mostly based on multimedia equipment. In the whole teaching process, the teacher applies PPT to show some classical art painting cases and guides them for independent production so as to master corresponding skills. Such teaching mode is relatively mature, but also has some defects. For instance, since students can view art painting effect only on the plane multimedia plane, teaching interactivity is poor and observation experience feeling is insufficient. Besides, teaching completeness is deficient. To improve the above defects, this paper constructed a teaching platform for Art Painting with VR technology. The platform has three major functions:

Firstly, it achieves virtual teaching and virtual experiment. Secondly, as a teaching resource library, it achieves online storage and sharing of teaching contents of art painting Production. 


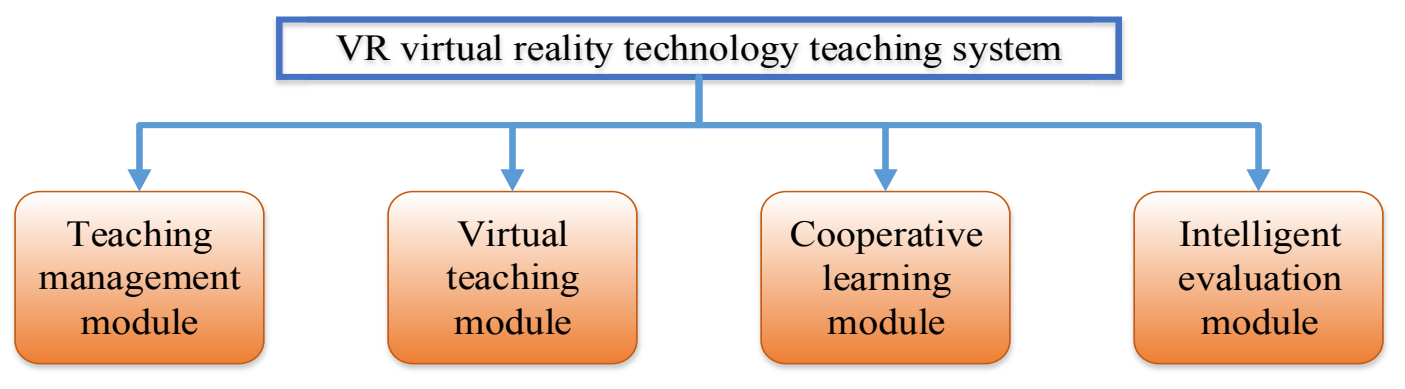

Figure 1. Module composition diagram of this system

Thirdly, virtual character replacement. In practical teaching, the teacher and students can enter the platform scene in the way of virtual substitute and apply platform resources for teaching, exchange and discussion. This achieves real online interactive virtual teaching.

\section{B. Analysis of module composition}

Based on the above design demand, this teaching system has multiple modules, mainly including teaching management module, virtual teaching module, cooperative learning module and intelligent evaluation module. Fig.1. shows module composition diagram of this system.

The figure 1 shows module composition of this teaching system. The specific functions of each module are as follows:

(1) Teaching management module: this module mainly completes conventional management of system, such as registration, authority setting, teacher and student information entry, course setting and teaching resource management etc.

(2) Virtual teaching module: this module has two functions. The first one is to achieve storage and sharing of teaching resources. The second one is to generate and display virtual teaching scene. For example, virtual electronic teaching plan, materials and design can be generated and displayed in $3 \mathrm{D}$ or plane form through this module.

(3) Cooperative learning module: this module is the characteristic of this system. With this module, the teacher and students can enter the system in the way of virtual substitute to view and operate art painting objects, gain teaching experience, discus and learn from each other. Through the exchange function on the platform such as message board and BBS, students can exchange learning experience.

(4) Intelligent evaluation module: with this module, the teacher can evaluate students' learning situation online. If the teachers fails to evaluate in time, the system can automatically count students' learning frequency and assignment completion times and quality to finish intelligent evaluation.

\section{Key techniques of platform}

This platform is based on VR technology. An intelligent and virtual teaching system was constructed by comprehensively applying VRML modeling and VRMLJAVA synchronous coordination as well as SQL Server database technology. In the specific design, this system adopts $\mathrm{B} / \mathrm{S}$ architecture, involving database, server and client. Various parts cooperate with each other to display teaching functions of the whole system Fig. 2 and Fig. 3 is structure diagram of key techniques of this system.

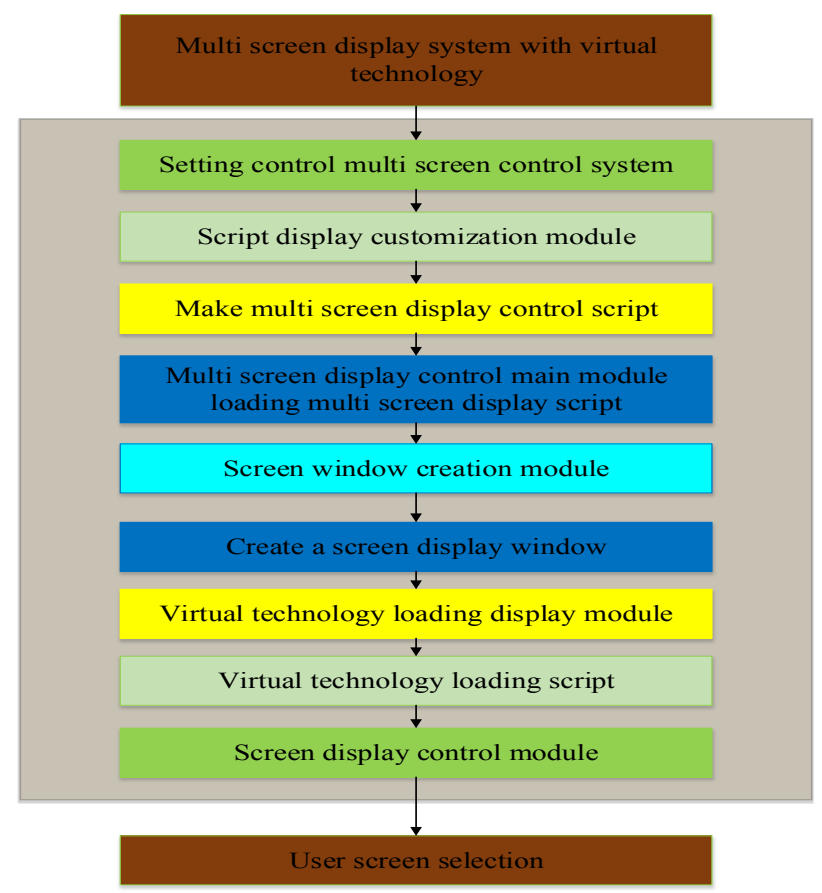

Figure 2. Structure diagram of key techniques of this system

Figure 3 shows composition structure diagram of key techniques of this system. Under three-layer $\mathrm{B} / \mathrm{S}$ architecture, mutual coordination function of key techniques is very prominent.

(1) Database technique: SQL Server2000 technology is used to construct database of this system. Meanwhile, VRML resource storage and database interconnection technique are integrated in the database. SQL Server2000 database is utilized to store VRML virtual teaching files and establish virtual teaching resource index. This technique achieves platform teaching resource storage, search and sharing functions.

(2) Server technique: the server is constructed with WIN2000 Server2000 operating system. This server utilizes JAVA technology to receive information and simulate art painting data. JAVA development tools at the server include JDK1.3 and JAVA3D. In the specific operation, the server can achieve internet and LAN communication access and complete virtual service function.

(3) Client technique: it mainly adopts integration of VRML and JAVA Applet. In the specific operation, the client operates in the form of JAVA Applet, displays virtual scene through VRML programming interface EAI and accomplishes display of course resources of art painting Production. 


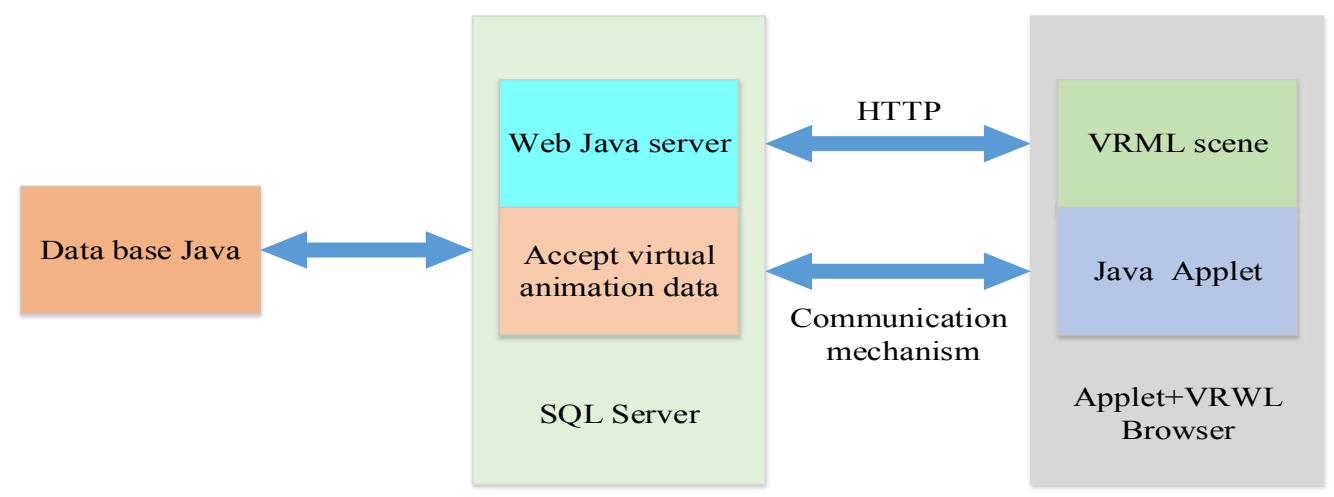

Figure 3. Structure diagram of key techniques of this system

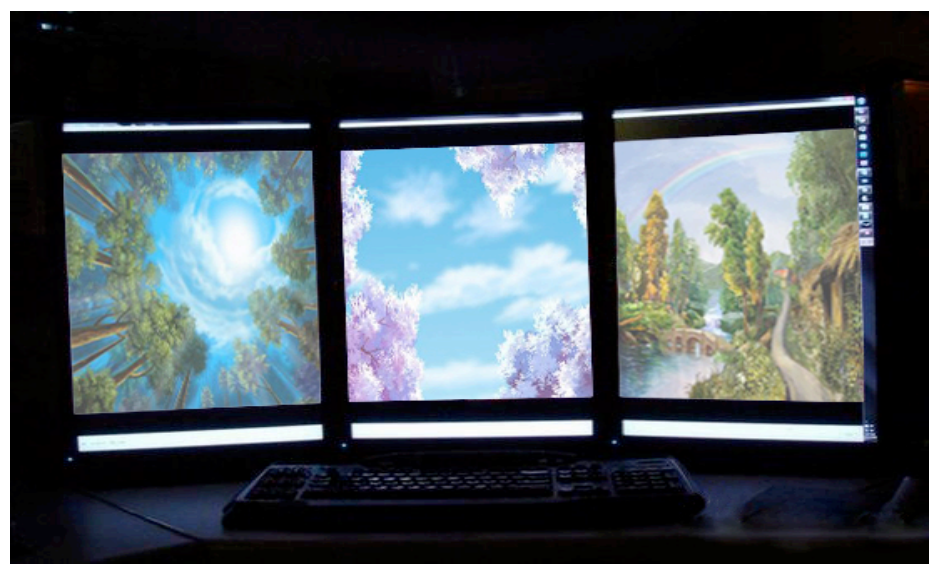

Figure 4. Application of multi-screen VR technology in the course of art painting

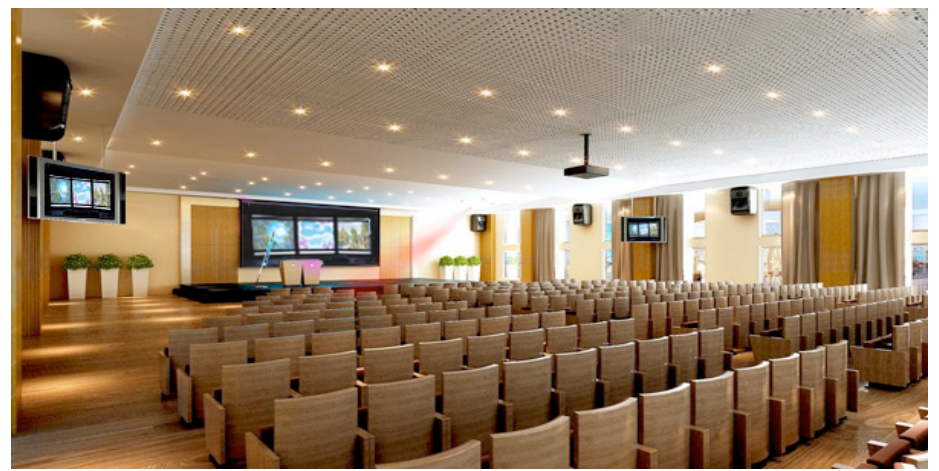

Figure 5. Application of multi-screen VR technology in the course of art painting

\section{Teaching application process}

Teaching application Effect of this system is shown in figure 4 and figure 5 .

Figure 4 and figure 5 show the teaching process of this system. In the specific teaching application, since the system is based on three-layer B/S architecture, the teacher can construct VR scene at the server and import teaching resources of art painting Production. In order to really embody interaction function of VR technology, both the teacher and students can log in their respective account number and enter virtual environment of the system in the capacity of virtual substitute for teaching practice and communication. Meanwhile, they finish art painting production, demonstration and modification in the virtual environment. The virtuality, interactivity and entertainment of the whole system are very outstanding.

\section{TEACHING EXPERIMENT APPLICATION}

\section{A. Selection of teaching objects}

Class 1 (experimental class, 56 students) and Class 2 (control class, 58 students) of 2014 animation production specialty were chosen as the objects. Both classes had no significant statistical difference in the age, gender, learning foundation and learning ability $(\mathrm{P}>0.05)$.

\section{B. Teaching design scheme}

Art Painting of animation production specialty was chosen as the teaching content, including 48 class hours. In the specific teaching design, VR teaching platform was used for the experimental control, while traditional multimedia equipment was applied for the control class. After the course ended, questionnaire and quantitative statistics 
were adopted to collect and analyze examination scores and learning cognition etc. of both classes.

\section{Statistical method}

SPSS software was applied for sample analysis of students' examination scores. $\mathrm{P}<0.05$ means the difference has statistical significance. Besides, EXCEL software was used for data statistics of teaching indexes and the data were made into graphs for analysis so as to make teaching evaluation results clear at a glance.

\section{Teaching implementation steps}

\section{1) Steps of control class}

During teaching the control class, the teacher adopted traditional PPT demonstration method for teaching. To be more specific, the teacher took multimedia courseware as the teaching carrier and combined verbal explanation, question answering in classroom and assignment arrangement to implement teaching.

\section{2) Steps of experimental class}

During teaching the experimental class, the teacher introduced VR technology for teaching. The teaching process was implemented according to Fig.3. In the specific practice, a teaching mode of viewing and experience evaluation gradually formed through exploration, introspection and optimization.

First, the teacher led the students in experimental class in VR teaching training room and introduced all kinds of art painting teaching cases. Each student and the teacher had a specific system login account number. In the teaching practice, both parties logged in the system with the account number, established virtual identity with system setting function at the server and client, and wore the special glasses for VR teaching to view art painting cases.

When viewing teaching in Stage I was finished, the teacher grouped the students in the class. According to teaching cases in Stage I, each group completed Art Painting with the software under virtual environment. The teacher could communicate online with students through BBS and message board through cooperation module on the platform. Students; all operations and viewing were completed under virtual scene. The art painting assignment was sent to the teacher with HTTP transmission function between client and server on the platform. VR teaching experience scene is as follows.

After receiving the works of all students, the teacher carried out online evaluation of students' works through intelligent evaluation module and transmitted the evaluation results to students. Because the teacher adopted sound and optimal evacuation mode (i.e. improve and modify the works on the basis of the works submitted by students), the works sent to students were improved and modified works. Students could utilize VR platform to view modified works and compare the modified works with the original works to look for the gap and improve Art Painting skills.

\section{TEACHING Result AND Discussion}

After the course lasting for 48 class hours ended, the teacher used questionnaire survey, theory examination and practice examination to record and process learning indexes of experimental class and control class. The detailed statistical results are shown in Figure 6.
As shown in Fig.6, in statistics of theory examination scores and practice examination scores, the performance of control class is significantly inferior to that of experimental class $(\mathrm{P}<0.001)$. As for the comparison of theory scores, the score of experimental class is $90.21 \pm 7.45$, while the score of control class is $78.54 \pm 6.84$. With regard to the comparison of practice scores, the score of experimental class is $88.45 \pm 8.72$, while the score of control class is $75.18 \pm 7.67$. There is significant difference. Moreover, about survey statistics of learning interest data, the differences of both classes are also significant. The detailed results are as figure 7.

As shown in Figure 7, during investigation of course learning interest, data differences of both classes are significant. $62.5 \%$ of students in the experimental class are very interested in the course, while only $34.5 \%$ of students in the control class are very interested in the course. $16.1 \%$ of students in the experimental class are not interested in the course, while this proportion is as high as $39.7 \%$ for the students in the control class. Wilcoxon rank sum test shows the differences have statistical significance $(\mathrm{P}<0.001)$.

Art Painting is a required course of college animation production specialty. This course consists of theory and practice and aims to train students' skills to produce and demonstrate animation with software. It plays a positive role in cultivating students' sense of color, 3D and spatial imagination. Under traditional teaching mode, most teachers get used to adopting explanation teaching method. Such teaching mode is old-fashioned and limited to classroom. In the whole learning process, students; experience feeling for Art Painting graphs is not strong. Based on VR technology, this paper designed a VR teaching system. The outstanding characteristic of this system is that, the teacher and students can enter the virtual scene through setting virtual identity, and carry out teaching exchange, assignment submission, performance evaluation, case viewing and animation production in the scene. The teaching environment is virtual and real. Thus, this teaching system greatly improves students' experience feeling. Based on the above teaching system, the teacher deigned a viewing and experience evaluation. This teaching mode completely focuses on the system and pays attention to promoting students' classroom experience feeling. Hence, this teaching system is very advanced.

On the whole, if the above system is applied in teaching, the teaching scene is shifted to virtual training room from traditional classroom. The teaching effect doubles. However, this also puts forward high requirements for teachers to overall apply the system to design teaching process. After the teaching experiment ended, it is known from the interview with students that, more than $80 \%$ of students in the experimental class affirm the teaching effect of this system in Art Painting teaching. Besides, they expressed that the whole teaching form is very novel. They hope the teacher could design more and better teaching forms with this system, give full play to virtuality and entertainment of the system and carry out diversified teaching so as to motivate their learning interest to the largest extent. In conclusion, the introduction of this system in Art Painting teaching plays a great promotion role in improving students' examination scores and stimulating their learning interest. 


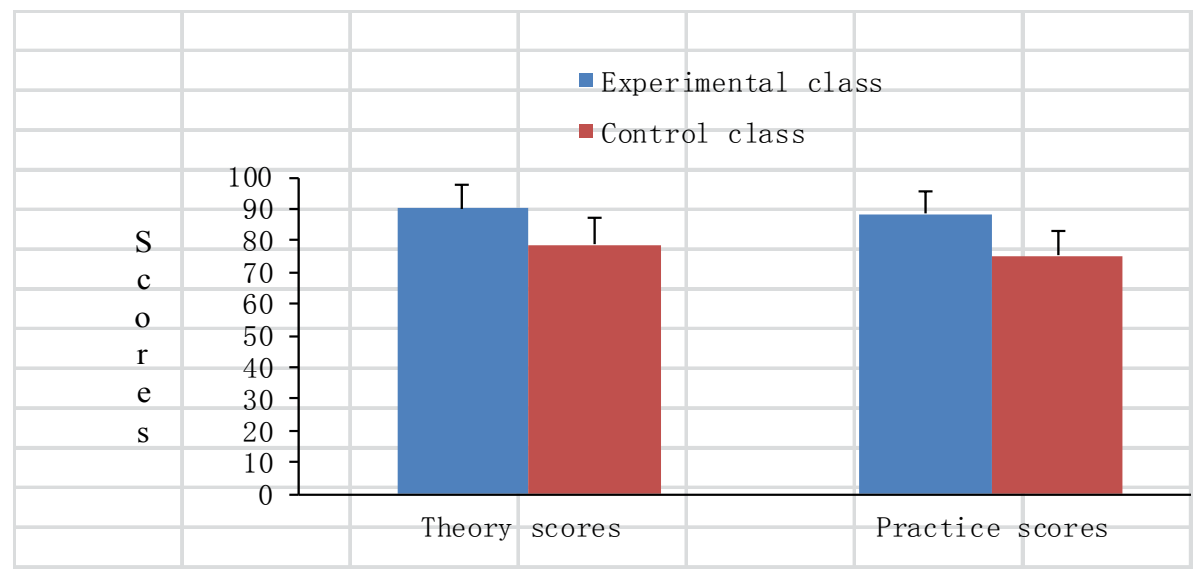

Figure 6. Diagram for homepage of multimedia interaction technology system

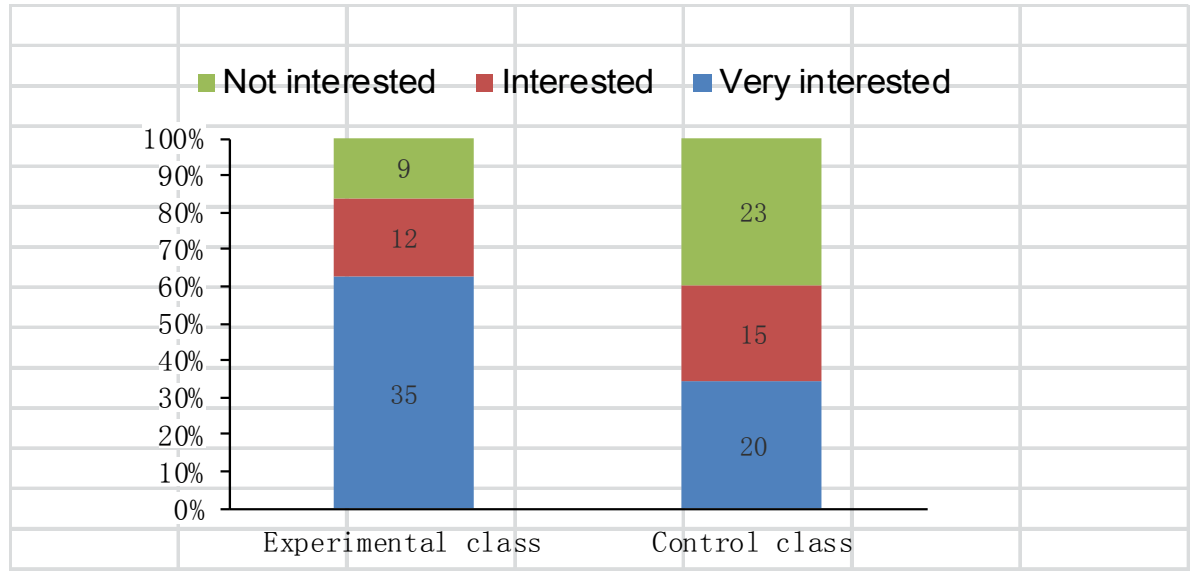

Figure 7. Statistical chart of learning interest of both classes

\section{CONCLUSION}

This paper designed and applied a teaching system based on VR technology. Teaching contrast experiment proves that, compared with traditional multimedia teaching means, this system has a significant effect on promoting teaching quality of art painting Production. Of course, the research also has some limitations. For instance, the sample size is small, which has certain influence on accuracy of teaching result statistics. Moreover, the application effect of this system in other courses of college animation production specialty is not verified. Therefore, it is necessary to conduct further research.

\section{REFERENCES}

[1] Sampaio A.Z., Martins O.P., "The application of virtual reality technology in the construction of bridge: The cantilever and incremental launching methods," Automation in construction, vol. 37, no. 1, pp. 58-67, January 2014. http://dx.doi.org/10.1016/j. autcon.2013.10.015

[2] Huang Y.C., Backman K.F., Backman S.J., et al., "Exploring the Implications of Virtual Reality Technology in Tourism Marketing: An Integrated Research Framework," International Journal of Tourism Research, vol. 18, no. 2, pp. 116-128, April 2016. http://dx.doi.org/10.1002/jtr.2038

[3] Erlandson B.E., Nelson B.C., Savenye W.C., "Collaboration modality, cognitive load, and science inquiry learning in virtual inquiry environments," Educational Technology Research and Development, vol. 58, no. 6, pp. 693-710, December 2010. http://dx.doi.org/10.1007/s11423-010-9152-7
[4] Yuan Q., Wu Y.C., Li, J., et al., "Reference and application of VR technology in Acupuncture and Moxibustion Therapy teaching," Guiding Journal of Traditional Chinese Medicine and Pharmacy, vol. 21, no. 21, pp. 109-111, November 2015.

[5] Liu L.L., Lin Y.T., Wang Y.F., "Study on 3D animation resource construction and interactive design in virtual Learning environment," China Educational Technology, vol. 21, no. 2, 123-128, February 2014.

[6] Tian B., "Research on improving 3D animation teaching with motion capture technology," Information Construction, vol. 18, no. 11, pp. 325+327, November 2015 .

[7] Tian F., "Theoretical research based on 3D animation and VR technology," Electronics World, vol. 22, no. 15, 148-149, August 2015.

[8] Dai Q.Y., Wang J.D., Liu R.T., et al., "Inverter Power Monitoring System Based on VRML Virtual Reality Technology," International Journal of Smart Home, vol. 7, no. 5, pp. 187-196, September 2013.

[9] Lomet D., "Microsoft SQL server's integrated database approach for modern applications and hardware," Proceedings of the VLDB Endowment, vol. 6, no. 11, pp. 1178-1179, August 2013. http://dx.doi.org/10.14778/2536222.2536248

\section{AUTHOR}

Chang Pan is a lecturer at School of Architecture \& Art Design, University of Science and Technology Liaoning, Anshan, 114051 China. Her research interests include Multi-screen VR Technology and Art Painting. (1076146761@qq.com)

Submitted 07 August 2016. Published as resubmitted by the author 09 September 2016. 